\title{
From the Urinary Catheter to the Prevalence of Three Classes of Integrons, $\beta$-Lactamase Genes, and Differences in Antimicrobial Susceptibility of Proteus mirabilis and Clonal Relatedness with Rep-PCR
}

\author{
Arezoo Mirzaei $\left(\mathbb{D},{ }^{1}\right.$ Bahram Nasr Esfahani $\mathbb{D}^{1},{ }^{1}$ Abbasali Raz ${ }^{(D)},{ }^{2}$ Mustafa Ghanadian $\left(\mathbb{D},{ }^{3}\right.$ \\ and Sharareh Moghim ${ }^{1}{ }^{1}$ \\ ${ }^{1}$ Department of Bacteriology and Virology, Faculty of Medicine, Isfahan University of Medical Science, Isfahan, Iran \\ ${ }^{2}$ Malaria and Vector Research Group (MVRG), Biotechnology Research Center (BRC), Pasteur Institute of Iran, Tehran, Iran \\ ${ }^{3}$ Department of Pharmacognosy, Isfahan Pharmaceutical Sciences Research Center, Isfahan University of Medical Science, \\ Isfahan, Iran \\ Correspondence should be addressed to Sharareh Moghim; moghim@med.mui.ac.ir
}

Received 21 March 2021; Revised 28 April 2021; Accepted 31 May 2021; Published 10 June 2021

Academic Editor: Joana Barbosa

Copyright (@ 2021 Arezoo Mirzaei et al. This is an open access article distributed under the Creative Commons Attribution License, which permits unrestricted use, distribution, and reproduction in any medium, provided the original work is properly cited.

\begin{abstract}
Introduction. Proteus mirabilis is a biofilm-forming agent that quickly settles on the urinary catheters and causing catheterassociated urinary tract infections. Thus, the spread of multidrug-resistant $P$. mirabilis isolates, with the ability to form a biofilm that carries integron, extended-spectrum $\beta$-lactamases (ESBLs), and plasmid-mediated colistin resistance genes ( $m c r$ ), represents a severe threat to managing nosocomial infectious diseases. This study is aimed at surveying the prevalence of ESBL, integrase, and $m c r$ genes of $P$. mirabilis, isolated from the catheter, to assess the differences in their antimicrobial susceptibility and clonal dissemination. Method. Microtiter plate assay was adopted to measure biofilm formation. The antimicrobial susceptibility was assessed by the disk diffusion method. Antimicrobial resistance genes (intI1, intI2, intI3, bla $a_{\mathrm{TEM}}, b l a_{\mathrm{CTX}-\mathrm{M}}, b l a_{\mathrm{SHV}}, m c r 1$, and mcr2) were detected by PCR. All of the isolates were characterized by repetitive sequence-based PCR. Result. From 385 collected catheters in patients admitted to the intensive care unit (ICU), 40 P. mirabilis were isolated. All of the isolates could form a biofilm. Proteus spp. had intrinsic resistance to tetracycline (95\%) and nitrofurantoin (92.5\%), which explains the high resistance prevalence. The most widely resistant antibiotic was trimethoprim-sulfamethoxazole (75\%). Thirty-three (82.5\%) isolates were classified as multidrug resistance (MDR). The prevalence of intI1 and intI2 genes was $60 \%$ and $25 \%$, respectively. In $6(15 \%)$ isolates, both genes were detected. The most frequent ESBL gene detected in all of the isolates was $b l a_{T E M}$. Also, no detection for morl and mcr2 antibiotic resistance genes was reported. Rep-PCR identified 39(GTG)5 types (G1-G39) of 40 isolates that 38 isolates had unique patterns. Conclusion. In this study, 82.5\% of isolates were MDR with high antibiotic resistance to trimethoprim-sulfamethoxazole. The intI1 and $b l a_{\text {TEM }}$ were the most prevalent genes in the integrase and ESBL gene family. High diversity was seen in the isolates with Rep-PCR. The increasing rate of MDR isolates with a high prevalence of resistance genes could be alarming and demonstrate the need for hygienic procedures to prevent the increased antibiotic resistance rate in the future.
\end{abstract}

\section{Introduction}

Proteus mirabilis is a charming polymorphic swarming persistent colonizer bacterium that strongly correlates with catheter blockage and urinary stone development. Complicated urinary tract infections (UTIs) at an alarming rate are expanding healthcare challenges, and $P$. mirabilis is the pathogen that must be noticed for causing those particular catheter-associated urinary tract infections (CAUTIs). $P$. mirabilis is a usual cause for complicated UTIs, and it becomes intricate in patients undergoing long-term indwelling urinary catheterization who may develop CAUTIs [1]. 
Such disorders cause difficulties by the inimitable ability of $P$. mirabilis to create crystalline biofilms, eventually leading to encrusted and blocked catheters [2]. Likewise, they could result in urine retention and reflux and, in severe conditions, septicemia and endotoxic shock in addition to trauma to the urethra and bladder mucosa due to removing the catheter [35]. CAUTIs present challenges to treatment strategies for different reasons, including the biofilm formation of $P$. mirabilis on catheters and urolith formation in the bladder and urinary tract, which could be created by multidrug-resistant isolates. Multidrug resistance (MDR) may be mediated by resistance agents located on chromosomes or mutations in a resident gene. However, it may also expand by attaining resistance genes through horizontal transfer [6].

These resistance genes, which are widely present on plasmids, transposons, and integrons, lead to the problem of rapid spread and treatment failure. In the past, most $P$. mirabilis isolates were susceptible to common antibiotic classes, but recent studies in different countries have indicated that antibiotic resistance among $P$. mirabilis isolates is increasing. The $\beta$-lactam resistance patterns of the P. mirabilis isolates have reported the production of various classes of extended-spectrum $\beta$-lactamases (ESBLs) [7].

The prevailing type of integrons discovered in clinical isolates is class 1 integron, which is highly associated with antibiotic resistance; therefore, they have been extensively studied [8]. Class 2 integrons stay in the second significant type of integrons obtained from clinical isolates. Usually, class 2 integrons are inserted in the nonreplicative transposon [9].

The extension of ESBL indicates a severe threat to managing nosocomial infectious diseases, causing problems for remedial choices of antimicrobial applications. The prevalence of integrons and characterized gene cassettes in Gramnegative bacteria integron-associated multidrug resistance has been investigated. However, it is seldom addressed in $P$. mirabilis [10]. Colistin is one of the last-resort drugs to treat infections caused by MDR Gram-negative bacteria. Although this bacterium is intrinsically colistin-resistant, it can carry plasmid-mediated colistin-resistant $(\mathrm{mcr})$ genes and is often overlooked and not screened for mcr. However, this bacterium can serve as a reservoir to transmit these genes to colistin-susceptible bacteria [11].

Various molecular methods, such as repetitive extragenic palindromic PCR (Rep-PCR), ribotyping, and pulse-field gel electrophoresis (PFGE), have been used to assess the genotypic diversity within several bacterial species [12].

Rep-based fingerprinting has been proved to be a fast and reliable tool to differentiate between Enterobacteriaceae populations. Rep-fingerprinting uses variations in conserved intergenic palindromic DNA sequences for PCR amplification and an isolate's characterization. These DNA elements are stable, noncoding intergenic repetitive sequences scattered across the genome and act as amplification targets to produce various bands $[13,14]$.

In this study, the prevalence of integrase genes (intI1, intI2, and intI3) and three ESBL genes $\left(b l a_{\mathrm{TEM}}, b l a_{\mathrm{CTX}-\mathrm{M}}\right.$, and $\left.b l a_{\mathrm{SHV}}\right)$, as well as $m c r 1$ and $m c r 2$, was investigated, and the comparison of integron-carrying and non-integron-carrying
MDR P. mirabilis isolated from the catheter was performed to assess the differences in their antimicrobial susceptibility and clonal dissemination. The clonal relationship for finding the origin of infection of the isolates was also evaluated with Rep-PCR.

\section{Material and Methods}

2.1. Bacterial Isolation. In this cross-sectional study from June 2019 to July 2020, 385 nonduplicate catheters (5 days15 days) from intensive care unit (ICU) patients were collected from various hospitals in Isfahan. The inclusion criteria for this study were that the collected catheters were from the patients without a primary urinary tract infection at admitting time; the minimum time of catheterization was five days.

P. mirabilis was isolated from the catheters. For this purpose, we followed the procedures of Mandakhalikar et al., with some modifications [15]. Briefly, catheters were cut into $1 \mathrm{~cm}$ segments and dipped in phosphate buffer saline (PBS) to discard loosely attached planktonic bacteria. The sample was transferred to $10 \mathrm{ml}$ PBS and vortexed vigorously for 1 min, then probe-based sonication was directed at $10 \mathrm{~W}$ (RMS) for 60-90 seconds, and another round of vortex for 1 minute at the highest speed was repeated. The catheter solution was then cultured on blood agar, Eosin Methylene Blue (EMB), MacConkey agar, and catalase, oxidase, IMViC, and urease are a few examples of conventional biochemical tests that were performed, and $P$. mirabilis suspected colonies were recultured to achieve a pure and single colony, and the ureG gene PCR was performed for genetic confirmation.

\subsection{Antibiotic Susceptibility Testing, ESBLs, and MDR} Detection. Antimicrobial resistance of the isolates to ampicillin-sulbactam $(10 / 10 \mu \mathrm{g})$, amoxicillin-clavulanic acid $(20 / 10 \mu \mathrm{g})$, ampicillin $(10 \mu \mathrm{g})$, nitrofurantoin $(300 \mu \mathrm{g})$, meropenem $(10 \mu \mathrm{g})$, cefotaxime $(30 \mu \mathrm{g})$, ceftazidime $(30 \mu \mathrm{g})$, ceftazidime-clavulanic acid $(30 / 10 \mu \mathrm{g})$, cefixime $(5 \mu \mathrm{g})$, aztreonam $(30 \mu \mathrm{g})$, amikacin $(30 \mu \mathrm{g})$, norfloxacin $(10 \mu \mathrm{g})$, ofloxacin $(5 \mu \mathrm{g})$, ciprofloxacin $(5 \mu \mathrm{g})$, tetracycline $(30 \mu \mathrm{g})$, and trimethoprim-sulfamethoxazole $(1.25 / 23.75 \mu \mathrm{g})$ was determined by the disk diffusion method on Mueller-Hinton agar overnight at $37^{\circ} \mathrm{C}$. The breakpoints for each antimicrobial agent were interpreted according to guidelines provided by the Clinical and Laboratory Standards Institute (CLSI) standards [16]. Furthermore, MDR isolates were defined, according to Magiorakos et al., when the isolates resist at least one agent in $\geq 3$ antimicrobial classes categorized in MDR isolates, the antibiotic classes that were considered for the definition of the MDR were cephalosporins (cefotaxime, ceftazidime, and cefixime), monobactams (aztreonam), carbapenems (meropenem), aminoglycosides (amikacin), quinolones (norfloxacin, ofloxacin, and ciprofloxacin), folate pathway antagonists (trimethoprim-sulfamethoxazole), penicillins (ampicillin), and beta-lactamase inhibitors (ampicillin-sulbactam and amoxicillin-clavulanic acid) [17]. In addition, the ESBL production of the isolates was detected by the double-disc diffusion synergy test [18]. 
TABLE 1: Sequences of primers used in this study.

\begin{tabular}{|c|c|c|c|}
\hline Gene & Primer sequence $\left(5^{\prime}-3^{\prime}\right)$ & Product $(\mathrm{bp})$ & Reference \\
\hline \multirow{2}{*}{ intI1 } & F: GGT CAA GGA TCT GGA TTT CG & \multirow{2}{*}{483} & \multirow{2}{*}[22]{} \\
\hline & R: ACA TGC GTG TAA ATC ATC GTC & & \\
\hline \multirow{2}{*}{ intI2 } & F: CAC GGA TAT GCG ACA AAA AGG T & \multirow{2}{*}{789} & \multirow{2}{*}{ [23] } \\
\hline & R: GTA GCA AAC GAG TGA CGA AAT G & & \\
\hline \multirow{2}{*}{ intI3 } & F: AGT GGG TGG CGA ATG AG & \multirow{2}{*}{600} & \multirow{2}{*}[24]{} \\
\hline & R: TGT TCT TGT ATC GCC AGG TG & & \\
\hline \multirow{2}{*}{$b l a_{\text {СТХ-M }}$} & F: TTT GCG ATG TGC AGT ACC AGT AA & \multirow{2}{*}{544} & \multirow{2}{*}{ [25] } \\
\hline & R: CGA TAT CGT TGG TGG TGC CAT A & & \\
\hline$b l a_{\mathrm{TEM}}$ & $\begin{array}{l}\text { F: AGT ATT CAA CAT TTC CGT GTC } \\
\text { R: GCT TAA TCA GTG AGG CAC CTA TC }\end{array}$ & 850 & [26] \\
\hline \multirow{2}{*}{$b l a_{\mathrm{SHV}}$} & F: ATG CGT TAT ATT CGC CTG TG & \multirow{2}{*}{862} & \multirow{2}{*}{ [27] } \\
\hline & R: GTT AGC GTT GCC AGT GCT CG & & \\
\hline \multirow{2}{*}{ morl } & F: CGG TCA GTC CGT TTG TTC & \multirow{2}{*}{309} & \multirow{2}{*}[28]{} \\
\hline & R: CTT GGT CGG TCT GTA GGG & & \\
\hline \multirow{2}{*}{$m c r 2$} & F: TGT TGC TTG TGC CGA TTG GA & \multirow{2}{*}{567} & \multirow{2}{*}{ [29] } \\
\hline & R: AGA TGG TAT TGT TGG TTG CTG & & \\
\hline \multirow{2}{*}{ ureG } & F: AGA ATA TAA TCA ACC ACT GCG TA & \multirow{2}{*}{514} & \multirow{2}{*}[30]{} \\
\hline & R: CAT TTT GGC TGT ATC CGC TTC & & \\
\hline Rep-typing & GTG GTG GTG GTG GTG & Variable & [31] \\
\hline
\end{tabular}

2.3. Biofilm Formation Assay. For this purpose, an overnight culture of $P$. mirabilis isolates was diluted $(1: 100)$ in TSB to reach the $0.5 \mathrm{McF}$ arland concentration, and $5 \mu \mathrm{l}$ of the diluted culture was inoculated in each well of polystyrene microtiter 96-well plates (Greiner, Germany). After $24 \mathrm{~h}$ incubation of the plates at $37^{\circ} \mathrm{C}$, the medium was removed, and the wells were washed carefully with double distilled water (DDW) and fixed by adding $200 \mu \mathrm{l}$ of ethanol (96\%) for 15 minutes. Next, the medium was removed, and the plate was left to dry. The biofilms were stained with $0.1 \%$ $(w / v)$ crystal violet for 20 minutes at $37^{\circ} \mathrm{C}$. Next, the biofilm was washed three times with DDW. Then, $200 \mu \mathrm{l}$ of ethanolacetic acid $(90: 10)$ was added to each well, and optical density (OD) was measured at $590 \mathrm{~nm}$ with an enzyme-linked immunosorbent assay (ELISA) microtiter plate reader. Each assay was done in triplicate, and the mean absorbance \pm standard deviation was calculated for all repetitions of the tests. Escherichia coli $\mathrm{K} 12$ and Pseudomonas aeruginosa ATCC 27853 were used as negative (weakly biofilm-forming) and positive (strong biofilm-forming) control strains, respectively [19].

2.4. PCR Amplification of bla, mcr1, and mcr2 Genes and Integrase Gene Detection. DNA was extracted by the phenolchloroform method described by Sambrook and Russell [20]. The purity and quality of the extracted DNA were evaluated by the NanoDropTM spectrophotometer (OD260/OD280 $\mathrm{nm}$ ratio $\geq 1.8$ ). PCR amplification was performed for bla genes, which coding for the $b l a_{\mathrm{TEM}}, b l a_{\mathrm{SHV}}, b l a_{\mathrm{CTX}-\mathrm{M}}$, and integron family (intI1, intI2, and intI3) using specific primers (Table 1). We used DNA of E. coli isolated and sequenced from Iranian Kidney Transplant Patients as control positive for integrase and ESBL genes, and DNA of $\mathrm{mcr}$ positive genes was taken from Pasteur Institute of Iran [21].

PCR conditions for all these genes were $3 \mathrm{~min}$ at $94^{\circ} \mathrm{C} ; 30$ cycles of 30 seconds at $94^{\circ} \mathrm{C}, 30$ seconds at $54^{\circ} \mathrm{C}$, and 30 seconds at $72^{\circ} \mathrm{C}$; and finally, $5 \mathrm{~min}$ at $72^{\circ} \mathrm{C}$. The amplicons were revealed by electrophoresis on a $1 \%$ agarose gel with $0.5 \mathrm{x}$ TBE (Tris-borate-EDTA) running buffer and subsequent exposure to UV light in the presence of a safe stain.

2.5. (GTG)5-Rep-PCR Fingerprinting Technique. We followed the methods of (GTG)5-PCR fingerprinting, which was described by Gevers et al. [31]. Analysis of amplicon (GTG)5-PCR patterns and construction of phylogenetic tree were carried out using the curve-based algorithm (Pearson correlation) (Applied Maths, Sint-Martens-Latem, Belgium) to create a similarity scale and an unweighted pair group using arithmetic average algorithm (UPGMA) for cluster analysis, the cut-off value in this $\mathrm{GTG}_{\mathrm{S}}$ typing predestinated $100 \%$ [32]. The band sizes were compared by using a $50 \mathrm{bp}$ ladder. The 15 -mer primer $\left(5^{\prime}\right.$-GTGG TGGTGGTGGTG- $\left.{ }^{\prime}\right)$ was used to amplify the repetitive sequences present in the chromosomal DNA of P. mirabilis. PCR condition was $3 \mathrm{~min}$ at $95^{\circ} \mathrm{C} ; 30$ cycles of 45 seconds at $94^{\circ} \mathrm{C}, 30$ seconds at $50^{\circ} \mathrm{C}$, and 45 seconds at $72^{\circ} \mathrm{C}$; and finally, $5 \mathrm{~min}$ at $72^{\circ} \mathrm{C}$. The PCR products were revealed by electrophoresis on a $1.5 \%$ agarose gel with $0.5 \mathrm{x}$ TBE at 2.5 hours with 65 voltage. This experiment was carried out three times. The graphical abstract of methods which performed in this study is shown in Figure 1.

2.6. Discriminatory Index Determination. A discriminatory index $(D)$ was calculated to varying levels of similarity index according to the formula. In the formula, $N$ represents the 


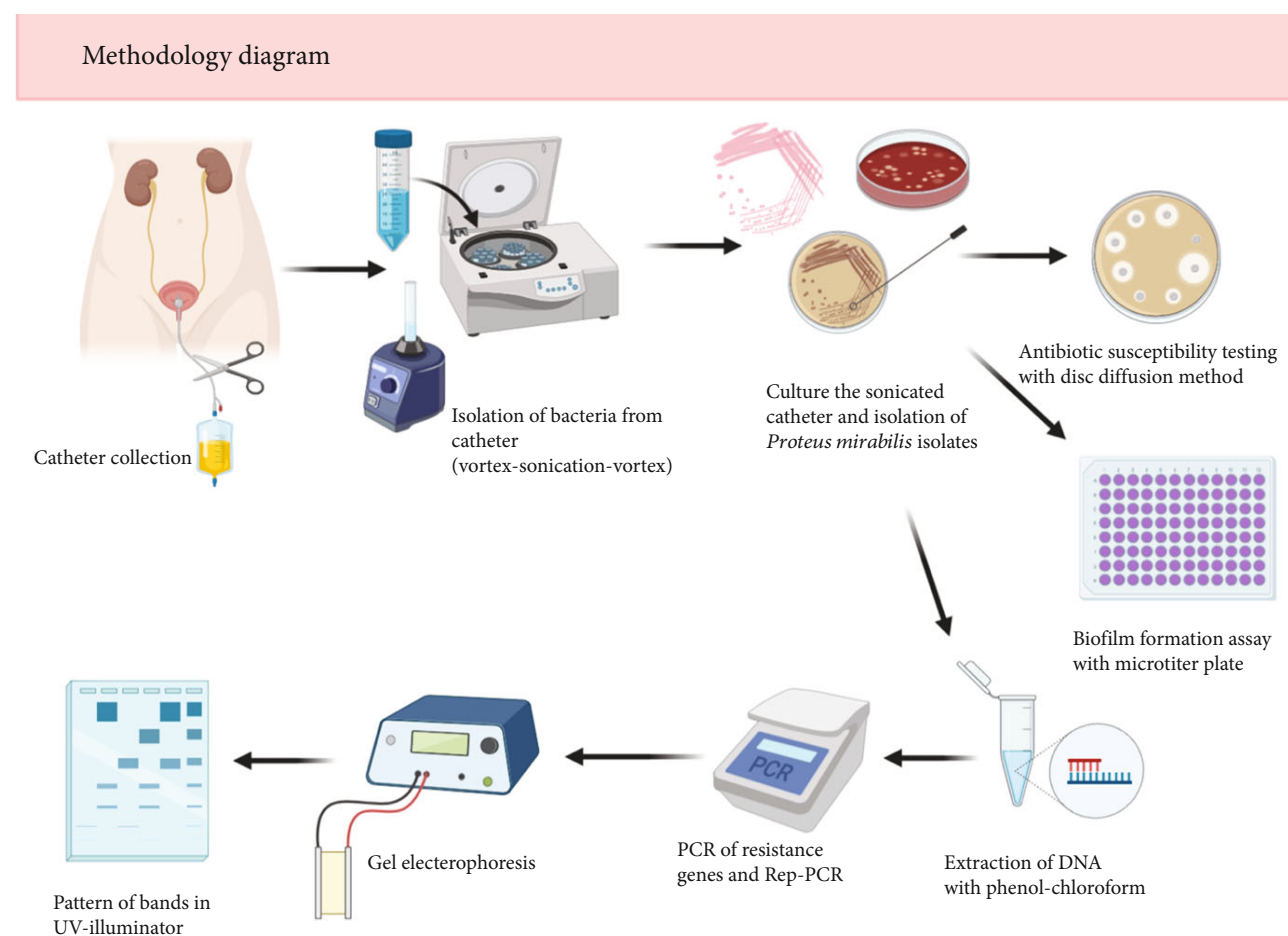

FIGURE 1: Graphical abstract of methodology.

number of unrelated strains evaluated, $S$ represents the number of distinct types, and $x j$ represents the number of strains belonging to the $j$ th category, assuming that strains are grouped into mutually exclusive groups.

$$
D=1-\frac{1}{N(N-1)} \sum_{j=1}^{s} x j(x j-1) .
$$

2.7. Statistical Analysis. Genotypic diversity among the isolates was calculated using Nei's distances described earlier by Weir [33]. The Rep-fingerprinting methods' discriminatory ability was assessed by calculating Simpson's diversity index, as described previously [34]. Statistical analysis was performed by SPSS Statistics (Version 16). Chi-square or Fisher's exact test was used to determine any statistical association. Statistical significance was regarded as $P$ values $<0.05$.

\section{Results and Discussion}

From 385 collected catheters in patients admitted to ICU, 40 P. mirabilis were isolated. In this study, $72.5 \%$ of $P$. mirabilis were isolated from females, and $27.5 \%$ were from males. The median age was 42.5 years old (5-75 years). The duration of patients' catheterization, which bacterial isolation was performed, was 5-15 days. Furthermore, the most bacterial isolation was from the ten days of patient catheterization (50\%). Patients who had a catheter for 10 to 15 days had moderate to strong biofilm formation; in addition, $50 \%$ of patients with short catheterization (7 days) had isolates with weak biofilm development (Table 2).
The antimicrobial-resistant patterns of isolates are shown in Figure 2. The resistant to tetracycline was 95\% followed by nitrofurantoin $(92.5 \%)$, trimethoprim/sulfamethoxazole (75\%), ciprofloxacin $(45 \%)$, cefotaxime $(42.5 \%)$, ofloxacin (40\%), ampicillin (35\%), meropenem (30\%), norfloxacin (25\%), cefixime and amoxicillin-clavulanate (22.5\%), aztreonam and amikacin (15\%), ceftazidime (7.5\%), and ampicillin-sulbactam (2.5\%). P. mirabilis is intrinsically resistant to tetracycline and nitrofurantoin which explains its high tolerance to these drugs. Of the $40 \mathrm{P}$. mirabilis isolates, $82.5 \%$ were MDR. Furthermore, ESBL was found in $7(17 \%)$ isolates.

All $P$. mirabilis isolated from catheters were able to produce biofilm. Of $40 \mathrm{P}$. mirabilis, twelve isolates (30\%) had strong biofilm ability (OD590 nm $\geq 2.5)$, twenty of them $(50 \%)$ were moderate biofilm producer $(1.5 \leq \mathrm{OD}$ $590 \mathrm{~nm}<2.5)$, and eight $(20 \%)$ of them had weak biofilm $(0.7 \leq$ OD590 $\mathrm{nm}<1.5)$ (Table 3$)$.

The frequency of three classes of the integron family is shown in Table 4 . The most prevalent gene was intI1 with $60 \%$ (24) of isolates and 25\% (10) of isolates had integrase 2 (intI2), and no detection for integrase 3; also, 15\% (6) of isolates had both integrase 1 and integrase 2 . The most prevalent gene in the bla ESBL family was observed in bla ${ }_{\mathrm{TEM}}$ genes with $100 \%$ (40) of isolates; $82.5 \%$ (33) of isolates had $b l a_{\mathrm{CTX}-\mathrm{M}}$ genes and no detection of $b l a_{\mathrm{SHV}}$. Also, PCRs targeting the $m c r-1$ and $m c r-2$ genes revealed no detection for these genes. Also, it demonstrated a significant relationship among resistance to trimethoprim/sulfamethoxazole, norfloxacin, and ofloxacin with a class 2 integron $(P<0.05)$.

Rep-PCR or (GTG)5-PCR fingerprints of 40 isolates generated 7 to 13 bands with the molecular size ranging from 
TABLE 2: The relationship between the duration of catheterization and the strength of biofilm formation.

\begin{tabular}{|c|c|c|c|c|}
\hline Duration of catheterization & Number of isolation (\%) & Strong biofilm (\%) & Moderate biofilm (\%) & Weak biofilm (\%) \\
\hline 15 days & $4(10)$ & $3(75)$ & $1(25)$ & $0(0)$ \\
\hline 10 days & $20(50)$ & $7(35)$ & $13(65)$ & $0(0)$ \\
\hline 7 days & $16(40)$ & $2(12.5)$ & $6(37.5)$ & $8(50)$ \\
\hline
\end{tabular}

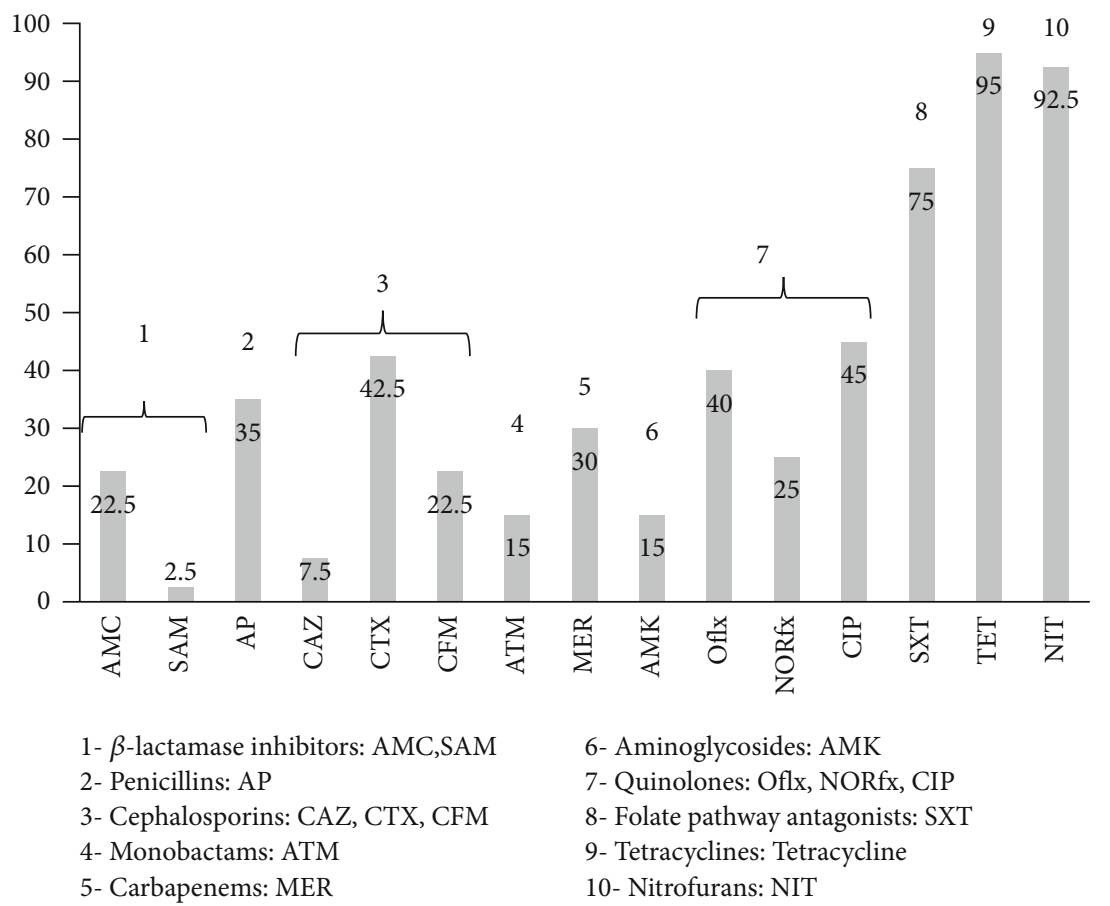

FIGURE 2: Frequency of antimicrobial resistance of Proteus mirabilis strains. Abbreviations: AMC: amoxicillin-clavulanate; SAM: ampicillinsulbactam; AP: ampicillin; CAZ: ceftazidime; CTX: cefotaxime: CFM: cefixime; ATM: aztreonam; MER: meropenem; AMK: amikacin; Oflx: ofloxacin; NORfx: norfloxacin; CIP: ciprofloxacin; SXT: trimethoprim/sulfamethoxazole; TET: tetracycline; NIT: nitrofurantoin.

TABLE 3: The severity of biofilm and integrase prevalence.

\begin{tabular}{|c|c|c|c|c|}
\hline Biofilm & $\begin{array}{c}\text { Integrase-1 positive } \\
\text { No. }(\%)\end{array}$ & $\begin{array}{c}\text { Integrase-2 positive } \\
\text { No. }(\%)\end{array}$ & $\begin{array}{l}\text { Total no } \\
\text { No. }(\%)\end{array}$ & $\begin{array}{c}\text { MDR } \\
\text { No. }(\%)\end{array}$ \\
\hline Strong & $8(66.6)$ & $3(25)$ & $12(30)$ & $11(91.6)$ \\
\hline Moderate & $13(65)$ & $4(20)$ & $20(50)$ & $15(75)$ \\
\hline Weak & $4(50)$ & $3(37.5)$ & $8(20)$ & $7(87.5)$ \\
\hline MDR & $22(66.6)$ & $10(30)$ & $33(82.5)$ & - \\
\hline
\end{tabular}

$250 \mathrm{bp}$ to more than $1 \mathrm{~kb}$. (GTG)5-PCR amplification identified $39(\mathrm{GTG}) 5$ types (G1-G39) of 40 isolates that 38 isolates had unique patterns (Figure 3 ). $D$ was calculated from a constructed phylogenetic tree, and according to the formula described before, discriminatory power was calculated at $99.8 \%$.

P. mirabilis is a common cause of complicated UTI, particularly in patients with functional or anatomical urinary tract abnormalities. Swarming motility can promote the migration of $P$. mirabilis from the periurethral area along the catheter surface into the urinary bladder and initiate CAUTIs in patients undergoing long-term catheterization.
There are limited data about the pathogenicity and antibiotic resistance of catheterized $P$. mirabilis in Iran. In this study, we evaluated the molecular characteristics of $P$. mirabilis isolated from CAUTI. The result of the current study showed that all of the isolates had the ability of biofilm formation, being in line with other studies $[30,35]$. The severity of biofilm formation depends on the day of catheterization.

The survival and recovery strategy, engrossed by some microbial species in front of rough environmental situations, can form a biofilm, thereby causing antibiotic resistance boosting. The severity of the biofilm-associated antimicrobial resistance of microorganisms is higher than their planktonic 
TABLE 4: Antibiotic resistance pattern of $P$. mirabilis isolates according to integrase 1, 2 positivity.

\begin{tabular}{|c|c|c|c|c|c|}
\hline Antibiotic & $\begin{array}{c}\text { No. resistant integrase } \\
1 \text { positive } \\
\text { No. }(\%) \\
N=24\end{array}$ & $\begin{array}{c}\text { No. resistant integrase } \\
1 \text { negative } \\
\text { No. }(\%) \\
N=16\end{array}$ & $\begin{array}{c}\text { No. resistant integrase } \\
2 \text { positive } \\
\text { No. }(\%) \\
N=10\end{array}$ & $\begin{array}{c}\text { No. resistant integrase } \\
2 \text { negative } \\
\text { No. }(\%) \\
N=30\end{array}$ & $P$ value \\
\hline AMC & $5(20.8)$ & $4(25)$ & $3(30)$ & $7(23.33)$ & NS \\
\hline SAM & $0(0)$ & $2(12.5)$ & $1(10)$ & $1(3)$ & NS \\
\hline ATM & $8(25)$ & $3(18.75)$ & $4(40)$ & $7(23.33)$ & NS \\
\hline TET & $23(95.8)$ & 15 (93.75) & $10(100)$ & $28(93.33)$ & NS \\
\hline MEM & $8(33.3)$ & $4(25)$ & $4(40)$ & $8(26.66)$ & NS \\
\hline NOR & $7(29.1)$ & $5(31.25)$ & $6(60)$ & $6(20)$ & $<0.05$ \\
\hline CAZ & $9(12.5)$ & $3(18.75)$ & $2(20)$ & $10(33.33)$ & NS \\
\hline Amp & $16(62.5)$ & $6(37.5)$ & $5(50)$ & $10(33.33)$ & NS \\
\hline OFX & $10(81)$ & $7(43.75)$ & $8(80)$ & $9(30)$ & $<0.05$ \\
\hline CFM & 7 (29.1) & $2(12.5)$ & $2(20)$ & $7(23.33)$ & NS \\
\hline SXT & $19(79.1)$ & $11(68.75)$ & $10(100)$ & $20(66.66)$ & $<0.05$ \\
\hline CIP & $16(50)$ & $9(56.25)$ & $9(90)$ & $16(53.33)$ & NS \\
\hline NIT & $24(95.8)$ & 15 (93.75) & $10(100)$ & $29(96.66)$ & NS \\
\hline AMK & $6(83)$ & $2(12.5)$ & $2(20)$ & $6(20)$ & NS \\
\hline CTX & $14(76)$ & $6(37.5)$ & $4(40)$ & $16(53.33)$ & NS \\
\hline
\end{tabular}

NS: not significant.

form [36]. The present study revealed an increasing growth in antibiotic resistance prevalence in $P$. mirabilis over the past years $[30,37]$. The ability of isolates to produce biofilm performs a matrix hindering the penetration of antimicrobial agents through biofilm layers. Moreover, the physiological attributes of microbial cells within biofilms, particularly persister cells, and acquiring of some resistance genes, including integrons family and ESBL genes, could explain biofilm resistance to antimicrobial agents [38]. Although Ojdana et al. [39] found the highest susceptibility to meropenem (100\%) in $P$. mirabilis isolates, we found the highest susceptibility to ampicillin-sulbactam (95\%); this may be due to differences in the types and amount of antibiotics used in different countries, geographical regions, years of study, and the fact that ampicillin-sulbactam was not used in the antibiotic test, which may explain the difference. The study also revealed a high prevalence of MDR isolates (82.5\%), being consistent with the findings of one study by Alabi et al. [37]. In addition, we found a report that contradicts our findings [30] so that we could justify that these differences may be due to differences in the date and location of isolation, as well as differences in the source of isolation (catheter, urine, wound, and blood). In our study, the isolated species were from the biofilm of the catheter causing higher antibiotic resistance, leading to higher MDR percentage.

This study demonstrated a significant association between resistance to trimethoprim/sulfamethoxazole, norfloxacin, and ofloxacin and a class 2 integron $(P<0.05)$. In other words, the presence of the integrase 2 gene in species could lead to resistance to antibiotics, such as trimethoprim/sulfamethoxazole, norfloxacin, and ofloxacin.

Previous studies confirmed that the presence of these elements, mostly class 1 integron, could be considered the evidence for a multidrug-resistant phenotype and associated with the increased frequency of resistance to some antibiotics, such as ciprofloxacin, sulfamethoxazole, and cotrimoxazole $[40,41]$. The results indicated a high prevalence of integron-positive isolates and a high antibiotic resistance level regarding the association between integron positive and antibiotic resistance.

In the light of the foregoing, the MDR phenomenon is often associated with the presence of integrons. The coexistence of the ESBL family and integrase genes increases the possibility of the emerging bacteria as a potential carrier of resistance determinants. Integrons can transfer, integrate, express, and distribute resistant agents, facilitating the MDR phenotype of the bacteria. Moreover, these elements entrap several resistance genes belonging to various classes. The prevalence of class 1,2, and 3 integrons among isolates of $P$. mirabilis investigated in this work is consistent with that reported by others [42-44] and inconsistent with the study conducted by Fursova et al. [45]; this difference could be owing to the time and the source of isolation.

With bacteria's ability to produce ESBL enzymes, the phenomenon of broad-spectrum resistance to $\beta$-lactam antibiotics is observed and confirmed, but the presence of genes not necessarily leads to the phenotypical appearance of ESBLs as numerous reports have demonstrated [39, 46]. Our analysis revealed such a relationship; therefore, $17.5 \%$ of isolates had the phenotypical occurrence of ESBLs. However, the ESBL gene prevalence was higher, which might result in the lack of expression of these genes. According to CLSI reports [47], Proteus species bring only the TEM betalactamase gene for a long time. At present, the spread of CTX-M is replacing TEM and SHV genes. Hence, the prevalence of bla $a_{\mathrm{CTX-M}}$ is increasing, being in line with our study 


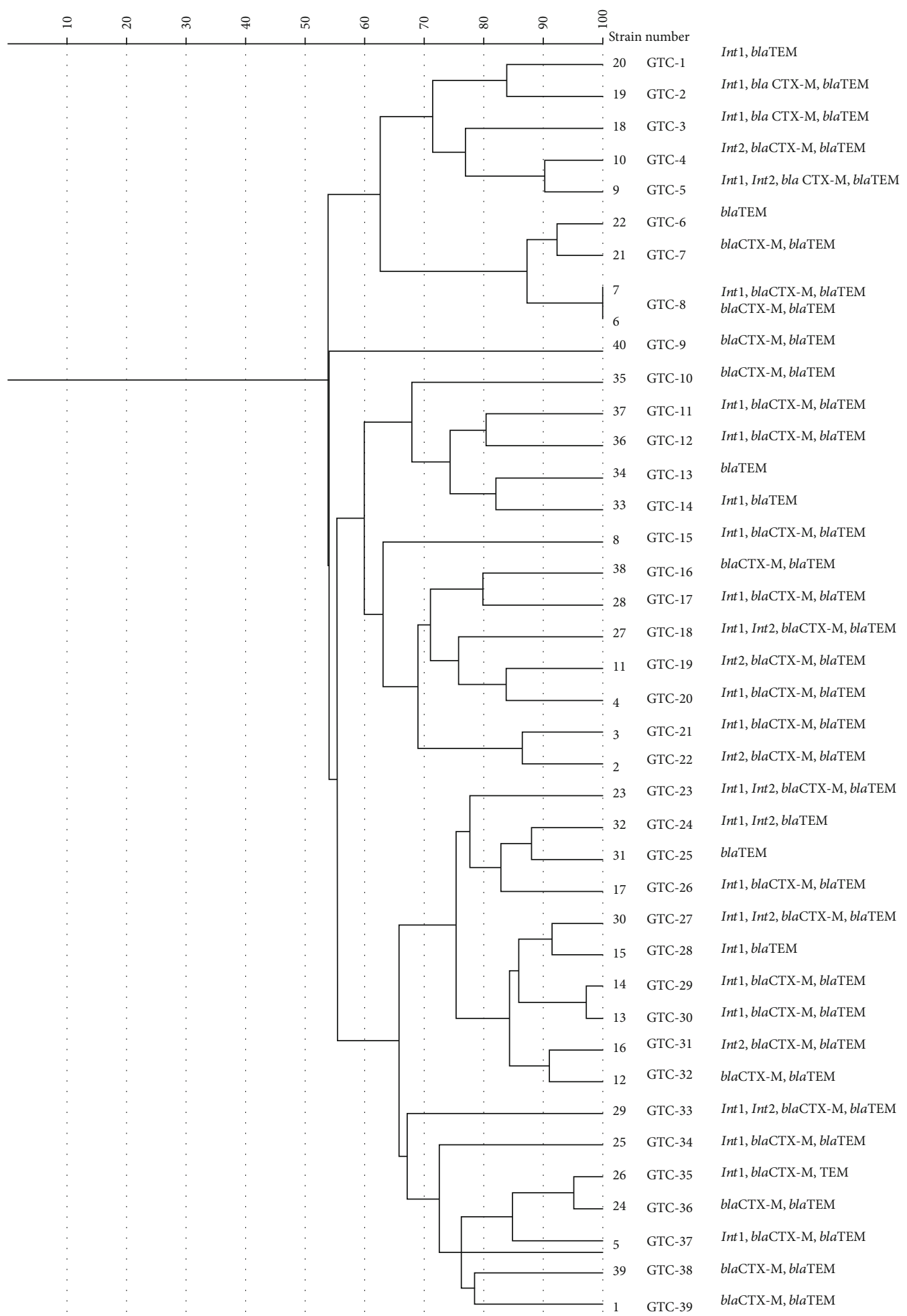

FIGURe 3: Dendrogram showing genetic relatedness of 40 strains of Proteus mirabilis determined by Rep-PCR analysis with Dice similarity coefficient and unweighted pair-group method with average linkages clustering method. Cut-off value: $100 \%$.

results [48] with this difference that $b l a_{\mathrm{TEM}}$ rampancy is one hundred percent; this could indicate the spread of ESBL genes among enteric bacteria and acquiring of those genes among the species as well as creation of new and more resistant species that is an alarming issue.
Surveying the epidemiological data over the past years could indicate a dramatic increase in antimicrobial resistance. Overall, the data present continually enhancing resistance to both $\beta$-lactams and other groups of antibiotics in the Enterobacteriaceae family's bacteria [26, 27]. Studies have 
demonstrated that the genes responsible for the production of CTX-M and TEM $\beta$-lactamases are more prevalent among tested strains than genes encoding SHV-type $\beta$-lactamases with no detection report. In this regard, the results of our study are in line with those of previous studies [37, 39, 45].

The steadfast intensify of concurrent resistance to different antibiotic classes significantly reduces the possibility of treatment of infections caused by ESBL producers and MDR isolates [49]. As a result, we aimed to analyze the level of resistance among ESBL-positive and MDR-tested strains. The different percent of resistance in other studies in different parts of the world is most likely due to variations in doctors' antibiotic prescribing prevalence and use in each country, which may be speculative. Other factors that may explain the disparities are the strains and sequence types that are the most prevalent ones in different regions of the world. Increased resistance to antibiotics has been observed in our study in proportion to other studies in Iran and other parts of the world. In this work, $63 \%$ of SXT-resistant isolates had the intI1 gene that was in contrast to further research reporting a 100\% relationship between the SXT resistance and the presence of intI1 [50]. We can explain this issue or the existence of intI2 or other resistance genes. As indicated by the study conducted by Alabi et al. [37], 100\% of MDR isolates had integrase genes, while this work revealed that $72.5 \%$ of MDR isolates had integrase genes. Until now, there is no reported existence of the intI3 gene in P. mirabilis isolates, being in line with other studies $[37,43]$. As we know, $P$. mirabilis has the intrinsic chromosomal resistance to colistin, but emergence of plasmid-mediated genes for colistin resistance in this bacterium could be a disaster that previous studies reported it to be very low in $m c r 1$ and $m c r 2$ genes [11]. In this study, fortunately, there is not a report of those genes. To control the dissemination of these elements and resistance genes, molecular typing of isolates could be sufficient. Molecular typing of P. mirabilis is the typical assay conducted to inspect genetic connectedness, discriminate between isolates, and exhibit the source of infection and transmission route with adequate accuracy to recognize the origin of nosocomial outbreaks.

Two efficient methods for Proteus characterization at the species level and designation of single strains of $P$. mirabilis are ribotyping and PFGE [51-53]. However, these methods have limitations for use in ordinary clinical laboratories, including being laborious, expensive, and time-consuming. An alternative simple and cost-benefit molecular typing, PCR-based, has been successfully used to identify P. mirabilis isolates [54].

The constructed phylogeny tree from Rep-PCR typing effectively identified the genetic relatedness of $P$. mirabilis isolated from the catheter. Rep-PCR (GTG) typing of forty catheter isolates in this study showed 39 types, of which two isolates from one hospital were put in one GTG type (GTG8) with $100 \%$ identity, which could be due to the dissemination of the isolates from the hospital environment to patients by personnel or nurses or nosocomial infection, and other isolates were put in single GTG type, which demonstrated high diversity among isolates. Rep-typing results show high discriminatory power, being completely in agree- ment with the study conducted by Bedenic et al. [55]. The study typing did not confirm the previous research conducted by Michelim et al. [56]. This is most likely due to inconsistencies in the samples and DNA extraction preparation processes, and the most significant reason is the disparity in primers used in this analysis, which differs from our primers.

This GTG8 type, between two isolates, has a similar resistance gene, but the lack of the intI1 gene has been observed for one of them, which might because the gene release has not yet occurred. The high diversity of isolates in the phylogenic tree was seen in the previous study [30].

The limitation of this study was the lack of a modern technique, such as multilocus sequence typing (MLST) and PFGE, to determine the clonality of isolates due to limited financial sources.

\section{Conclusions}

In this study, $82.5 \%$ of isolates were MDR with high antibiotic resistance to trimethoprim-sulfamethoxazole. The intI and $b l a_{\mathrm{TEM}}$ were the most prevalent genes in the integron and ESBL gene family. High diversity was observed in isolates with Rep-PCR. The outcome of persistence MDR strains under antimicrobial selective pressure in the hospital environment will increase both the chance of an advantageous mutation and the opportunity to acquire additional resistance genes. Nevertheless, the existence of the same type of isolates could be an alarming issue for healthcare providers' hygiene conditions to eliminate these infections particularly spread of resistance genes and highlight the importance of sporadically epidemiological studies and methods with high discriminatory power.

\section{Data Availability}

The data used to support the findings of this study are included within the article.

\section{Conflicts of Interest}

The authors declare that they have no conflict of interest.

\section{Acknowledgments}

This research benefited from a grant from Isfahan University of Medical Sciences. This work was supported by Isfahan University of Medical Sciences, Isfahan, I.R. Iran, through Grant No. 398353.

\section{References}

[1] R. T. Jamil, L. A. Foris, and J. Snowden, Proteus mirabilis infections, StatPearls Publishing, 2017.

[2] S. M. Jones, J. Yerly, Y. Hu, H. Ceri, and R. Martinuzzi, "Structure of Proteus mirabilis biofilms grown in artificial urine and standard laboratory media," FEMS Microbiology Letters, vol. 268, no. 1, pp. 16-21, 2007.

[3] C.-Y. Chen, Y.-H. Chen, P.-L. Lu, W.-R. Lin, T.-C. Chen, and C.-Y. Lin, "Proteus mirabilis urinary tract infection and 
bacteremia: risk factors, clinical presentation, and outcomes," Journal of Microbiology, Immunology, and Infection, vol. 45, no. 3, pp. 228-236, 2012.

[4] S. Vaidyanathan, B. M. Soni, P. L. Hughes, G. Singh, and T. Oo, "Severe Ventral Erosion of Penis Caused by Indwelling Urethral Catheter and Inflation of Foley Balloon in Urethra-Need to Create List of "Never Events in Spinal Cord Injury" in order to Prevent These Complications from Happening in Paraplegic and Tetraplegic Patients," Advances in urology, vol. 2010, Article ID 461539, 5 pages, 2010.

[5] R. Wasfi, S. M. Hamed, M. A. W. Abd Allah, and L. Ismail, "Proteus mirabilis biofilm: development and therapeutic strategies," Frontiers in Cellular and Infection Microbiology, vol. 10, p. $414,2020$.

[6] M. A. Leverstein-van Hall, H. E. M. Blok, A. R. T. Donders, A. Paauw, A. C. Fluit, and J. Verhoef, "Multidrug resistance among Enterobacteriaceae is strongly associated with the presence of integrons and is independent of species or isolate origin," The Journal of Infectious Diseases, vol. 187, no. 2, pp. 251-259, 2003.

[7] C.-M. Chen, C.-H. Lai, H.-J. Wu, and L.-T. Wu, "Genetic characteristic of class 1 integrons in proteus mirabilis isolates from urine samples," BioMedicine, vol. 7, no. 2, p. 9, 2017.

[8] A. Fluit and F. J. Schmitz, "Class 1 integrons, gene cassettes, mobility, and epidemiology," European Journal of Clinical Microbiology \& Infectious Diseases, vol. 18, no. 11, pp. 761770, 1999.

[9] Q. Wei, Q. Hu, S. Li et al., "A novel functional class 2 integron in clinical Proteus mirabilis isolates," The Journal of Antimicrobial Chemotherapy, vol. 69, no. 4, pp. 973-976, 2014.

[10] R. A. Bonomo, "Multiple antibiotic-resistant bacteria in longterm-care facilities: an emerging problem in the practice of infectious diseases," Clinical Infectious Diseases, vol. 31, no. 6, pp. 1414-1422, 2000.

[11] Z. Hmede and I. I. Kassem, "First report of the plasmid-borne colistin resistance gene ( $m c r-1)$ in Proteus mirabilis isolated from a toddler in non-clinical settings," IDCases, vol. 18, p. e00651, 2019.

[12] B.-K. Hahm, Y. Maldonado, E. Schreiber, A. K. Bhunia, and C. H. Nakatsu, "Subtyping of foodborne and environmental isolates of Escherichia coli by multiplex-PCR, rep-PCR, PFGE, ribotyping and AFLP," Journal of Microbiological Methods, vol. 53, no. 3, pp. 387-399, 2003.

[13] K. Baldy-Chudzik and M. Stosik, "Specific genomic fingerprints of Escherichia coli strains with repetitive sequences and PCR as an effective tool for monitoring freshwater environments," Polish Journal of Environmental Studies, vol. 14, no. 5, 2005.

[14] B. R. Mohapatra and A. Mazumder, "Comparative efficacy of five different rep-PCR methods to discriminate Escherichia coli populations in aquatic environments," Water Science and Technology, vol. 58, no. 3, pp. 537-547, 2008.

[15] K. D. Mandakhalikar, J. N. Rahmat, E. Chiong, K. G. Neoh, L. Shen, and P. A. Tambyah, "Extraction and quantification of biofilm bacteria: method optimized for urinary catheters," Scientific reports, vol. 8, no. 1, p. 8069, 2018.

[16] Clinical and Laboratory Standards Institute, Performance Standards for Antimicrobial Susceptibility Testing. 28th ed. CLSI supplement M100, Clinical and Laboratory Standards Institute, Wayne, PA, USA, 2018.
[17] A.-P. Magiorakos, A. Srinivasan, R. B. Carey et al., "Multidrugresistant, extensively drug-resistant and pandrug-resistant bacteria: an international expert proposal for interim standard definitions for acquired resistance," Clinical Microbiology and Infection, vol. 18, no. 3, pp. 268-281, 2012.

[18] L. Drieux, F. Brossier, W. Sougakoff, and V. Jarlier, "Phenotypic detection of extended-spectrum $\beta$-lactamase production in Enterobacteriaceae: review and bench guide," Clinical Microbiology and Infection, vol. 14, pp. 90-103, 2008.

[19] G. A. O’Toole, "Microtiter dish biofilm formation assay," Journal of visualized experiments: JoVE, vol. 47, 2011.

[20] J. Sambrook and D. W. Russell, "Purification of nucleic acids by extraction with phenol: chloroform," Cold Spring Harbor Protocols, vol. 2006, no. 1, 2006.

[21] M. Halaji, S. Shahidi, A. Atapour, B. Ataei, A. Feizi, and S. A. Havaei, "Characterization of extended-spectrum $\beta$-lactamase-producing uropathogenic Escherichia coli among Iranian kidney transplant Patients," Infection and drug resistance, vol. Volume 13, pp. 1429-1437, 2020.

[22] D. Mazel, B. Dychinco, V. A. Webb, and J. Davies, “Antibiotic resistance in the ECOR collection: integrons and identification of a novel aad gene," Antimicrobial Agents and Chemotherapy, vol. 44, no. 6, pp. 1568-1574, 2000.

[23] A. Gündoğdu, Y. B. Long, T. L. Vollmerhausen, and M. Katouli, "Antimicrobial resistance and distribution of sul genes and integron-associated intI genes among uropathogenic Escherichia coli in Queensland, Australia," Journal of Medical Microbiology, vol. 60, no. 11, pp. 1633-1642, 2011.

[24] C. Goldstein, M. D. Lee, S. Sanchez et al., "Incidence of class 1 and 2 integrases in clinical and commensal bacteria from livestock, companion animals, and exotics," Antimicrobial Agents and Chemotherapy, vol. 45, no. 3, pp. 723-726, 2001.

[25] M. Edelstein, M. Pimkin, I. Palagin, I. Edelstein, and L. Stratchounski, "Prevalence and molecular epidemiology of CTX-M extended-spectrum $\beta$-lactamase-producing Escherichia coli and Klebsiella pneumoniae in Russian hospitals," Antimicrobial Agents and Chemotherapy, vol. 47, no. 12, pp. 3724-3732, 2003.

[26] J. R. Johnson and A. L. Stell, "Extended virulence genotypes of Escherichia coli strains from patients with urosepsis in relation to phylogeny and host compromise," The Journal of Infectious Diseases, vol. 181, no. 1, pp. 261-272, 2000.

[27] I. Wiegand, H. K. Geiss, D. Mack, E. Stürenburg, and H. Seifert, "Detection of extended-spectrum beta-lactamases among Enterobacteriaceae by use of semiautomated microbiology systems and manual detection procedures," Journal of Clinical Microbiology, vol. 45, no. 4, pp. 1167-1174, 2007.

[28] Y.-Y. Liu, Y. Wang, T. R. Walsh et al., "Emergence of plasmidmediated colistin resistance mechanism MCR-1 in animals and human beings in China: a microbiological and molecular biological study," The Lancet Infectious Diseases, vol. 16, no. 2, pp. 161-168, 2016.

[29] B. B. Xavier, C. Lammens, R. Ruhal et al., "Identification of a novel plasmid-mediated colistin-resistance gene, $\mathrm{mcr}-2$, in Escherichia coli, Belgium, June 2016," Eurosurveillance, vol. 21, no. 27, 2016.

[30] A. Mirzaei, M. Habibi, S. Bouzari, and M. R. A. Karam, "Characterization of antibiotic-susceptibility patterns, virulence factor profiles and clonal relatedness in Proteus mirabilis isolates from patients with urinary tract infection in Iran," Infection and drug resistance, vol. Volume 12, pp. 3967-3979, 2019. 
[31] D. Gevers, G. Huys, and J. Swings, "Applicability of rep-PCR fingerprinting for identification of Lactobacillus species," FEMS Microbiology Letters, vol. 205, no. 1, pp. 31-36, 2001.

[32] N. Khare, M. Kaushik, J. P. Martin, A. Mohanty, and P. Gulati, "Genotypic diversity in multi-drug-resistant E. coli isolated from animal feces and Yamuna River water, India, using repPCR fingerprinting," Environmental Monitoring and Assessment, vol. 192, no. 11, pp. 1-13, 2020.

[33] B. S. Weir, Genetic data analysis. Methods for discrete population genetic data, Sinauer Associates, Inc. Publishers, 1990.

[34] P. R. Hunter and M. A. Gaston, "Numerical index of the discriminatory ability of typing systems: an application of Simpson's index of diversity," Journal of Clinical Microbiology, vol. 26, no. 11, pp. 2465-2466, 1988.

[35] W. D. de Oliveira, M. G. L. Barboza, G. Faustino et al., "Virulence, resistance and clonality of Proteus mirabilis isolated from patients with community-acquired urinary tract infection (CA-UTI) in Brazil," Microbial Pathogenesis, vol. 152, 2020.

[36] N. Høiby, T. Bjarnsholt, M. Givskov, S. Molin, and O. Ciofu, "Antibiotic resistance of bacterial biofilms," International Journal of Antimicrobial Agents, vol. 35, no. 4, pp. 322-332, 2010.

[37] O. S. Alabi, N. Mendonça, O. E. Adeleke, and G. J. da Silva, "Molecular screening of antibiotic-resistant determinants among multidrug-resistant clinical isolates of Proteus mirabilis from SouthWest Nigeria," African Health Sciences, vol. 17, no. 2, pp. 356-365, 2017.

[38] B. S. Tseng, W. Zhang, J. J. Harrison et al., "The extracellular matrix protects Pseudomonas aeruginosa biofilms by limiting the penetration of tobramycin," Environmental Microbiology, vol. 15, no. 10, pp. 2865-2878, 2013.

[39] D. Ojdana, P. Sacha, P. Wieczorek et al., "The occurrence of blaCTX-M, blaSHV, and blaTEM genes in extendedspectrum $\beta$-lactamase-positive strains of Klebsiella pneumoniae, Escherichia coli, and Proteus mirabilis in Poland," International Journal of Antibiotics, vol. 2014, Article ID 935842, 7 pages, 2014.

[40] M. A. Rezaee, V. Sheikhalizadeh, and A. Hasani, "Detection of integrons among multi-drug resistant (MDR) Escherichia coli strains isolated from clinical specimens in northern west of Iran," Brazilian Journal of Microbiology, vol. 42, no. 4, pp. 1308-1313, 2011.

[41] M. Yekani, M. Y. Memar, H. B. Baghi, F. Y. Sefidan, N. Alizadeh, and R. Ghotaslou, "Association of integrons with multidrug-resistant isolates among phylogenic groups of uropathogenic Escherichia coli," Microbiology Research, vol. 9, no. $1,2018$.

[42] P. A. White, C. J. McIver, and W. D. Rawlinson, "Integrons and gene cassettes in theenterobacteriaceae," Antimicrobial Agents and Chemotherapy, vol. 45, no. 9, pp. 2658-2661, 2001.

[43] A. Reyes, H. Bello, M. Domínguez, S. Mella, R. Zemelman, and G. González, "Prevalence and types of class 1 integrons in aminoglycoside-resistant Enterobacteriaceae from several Chilean hospitals," The Journal of Antimicrobial Chemotherapy, vol. 51, no. 2, pp. 317-321, 2003.

[44] C.-Y. Chang, L.-L. Chang, Y.-H. Chang, T.-M. LEE, and S.F. CHANG, "Characterisation of drug resistance gene cassettes associated with class 1 integrons in clinical isolates of Escherichia coli from Taiwan, ROC," Journal of Medical Microbiology, vol. 49, no. 12, pp. 1097-1102, 2000.
[45] N. K. Fursova, E. I. Astashkin, A. I. Knyazeva et al., "The spread of bla OXA-48 and bla OXA-244 carbapenemase genes among Klebsiella pneumoniae, Proteus mirabilis and Enterobacter spp. isolated in Moscow, Russia," Annals of clinical Microbiology and Antimicrobials, vol. 14, no. 1, pp. 1-9, 2015.

[46] S. Nijssen, A. Florijn, M. J. M. Bonten, F. J. Schmitz, J. Verhoef, and A. C. Fluit, "Beta-lactam susceptibilities and prevalence of ESBL-producing isolates among more than 5000 European Enterobacteriaceae isolates," International Journal of Antimicrobial Agents, vol. 24, no. 6, pp. 585-591, 2004.

[47] P. A. Wayne, Clinical and Laboratory Standards Institute: performance standards for antimicrobial susceptibility testing: 20th informational supplement, CLSI document M100-S20, 2010.

[48] H. A. Musa, M. A. M. Osman, Y. H. Abdelaziz, S. Mohamed, and M. Ibrahim-Saeed, "Distribution of extended-spectrum beta-lactamase TEM and CTX-M resistance genes among Proteus species isolated in Sudan," VacciMonitor, vol. 28, no. 2, pp. 80-84, 2019.

[49] H. Giamarellou and G. Poulakou, "Multidrug-resistant gramnegative infections," Drugs, vol. 69, no. 14, pp. 1879-1901, 2009.

[50] M. A. Leverstein-van Hall, A. Paauw, A. T. A. Box, H. E. M. Blok, J. Verhoef, and A. C. Fluit, "Presence of integronassociated resistance in the community is widespread and contributes to multidrug resistance in the hospital," Journal of Clinical Microbiology, vol. 40, no. 8, pp. 3038-3040, 2002.

[51] S. Pignato, G. M. Giammanco, F. Grimont, P. A. D. Grimont, and G. Giammanco, "Molecular characterization of the genera Proteus, Morganella, and Providencia by ribotyping," Journal of Clinical Microbiology, vol. 37, no. 9, pp. 2840-2847, 1999.

[52] N. A. Sabbuba, E. Mahenthiralingam, and D. J. Stickler, "Molecular epidemiology of Proteus mirabilis infections of the catheterized urinary tract," Journal of Clinical Microbiology, vol. 41, no. 11, pp. 4961-4965, 2003.

[53] M. A. Pfaller, I. Mujeeb, R. J. Hollis, R. N. Jones, and G. V. Doern, "Evaluation of the discriminatory powers of the Dienes test and ribotyping as typing methods for Proteus mirabilis," Journal of clinical microbiology, vol. 38, no. 3, pp. 1077-1080, 2000.

[54] D. M. Olive and P. Bean, "Principles and applications of methods for DNA-based typing of microbial organisms," Journal of Clinical Microbiology, vol. 37, no. 6, pp. 1661-1669, 1999.

[55] B. Bedenić, N. Firis, V. Elveđi-Gašparović et al., "Emergence of multidrug-resistant Proteus mirabilis in a long-term care facility in Croatia," Wiener Klinische Wochenschrift, vol. 128, no. 11-12, pp. 404-413, 2016.

[56] L. Michelim, G. Muller, J. Zacaria, A. P. L. Delamare, S. O. P. da Costa, and S. Echeverrigaray, "Comparison of PCR-based molecular markers for the characterization of Proteus mirabilis clinical isolates," Brazilian journal of infectious diseases, vol. 12, no. 5, pp. 423-429, 2008. 